Check for updates

Cite this: RSC Adv., 2018, 8, 19707

Received 11th April 2018

Accepted 21st May 2018

DOI: $10.1039 / \mathrm{c} 8 \mathrm{ra03096k}$

rsc.li/rsc-advances

\section{Synthesis and antibacterial properties of a novel magnetic nanocomposite prepared from spent pickling liquors and polyguanidine}

\author{
Dung T. Nguyen, ${ }^{\text {ab }}$ Lan T. Pham, ${ }^{a}$ Ha T. T. Le, ${ }^{a b}$ Minh X. Vu, ${ }^{a}$ Hanh T. M. Le, ${ }^{a}$ \\ Huong T. M. Le, ${ }^{c}$ Nam H. Pham ${ }^{d}$ and Le T. Lu iD *ab
}

\begin{abstract}
Magnetic nanoparticles have received much interest for their application in wastewater treatment because of their easy retrieval and reuse. However, the methods used to synthesise high saturation magnetization magnetic nanoparticles require expensive and pure precursors. In the current study, we explore the potential for using spent pickling liquor, a wastewater solution from steel factories, as the iron precursor for preparing iron oxide nanoparticles. Here, magnetic $\mathrm{Fe}_{3} \mathrm{O}_{4}$ nanoparticles were synthesized via the oxidation-precipitation of spent pickling liquors using a saturated solution of calcium hydroxide at room temperature. The $\mathrm{Fe}_{3} \mathrm{O}_{4}$ nanoparticles were then modified with antibacterial polyguanidine to form a nanocomposite. It was found that monodisperse magnetic $\mathrm{Fe}_{3} \mathrm{O}_{4}$ nanoparticles with a size in the range 20-30 nm and a high saturation magnetization value of 73.9 emu g ${ }^{-1}$ were synthesised. The $\mathrm{Fe}_{3} \mathrm{O}_{4}$ nanoparticles were successfully encapsulated with polyguanidine to form an $\mathrm{Fe}_{3} \mathrm{O}_{4} /$ polyguanidine nanocomposite. FT-IR and TGA analysis results indicated the presence of the polymer on the $\mathrm{Fe}_{3} \mathrm{O}_{4}$ surface and the polymer content in the nanocomposite was about $15 \%(\mathrm{w} / \mathrm{w})$. The $\mathrm{Fe}_{3} \mathrm{O}_{4} /$ polyguanidine nanocomposite exhibited strong antibacterial activity against Escherichia coli (E. coli), demonstrating its potential for use in disinfecting wastewater
\end{abstract}

\section{Introduction}

In recent years, magnetic materials have attracted intensive interest due to their potential applications in various fields, including biomedicine, ${ }^{\mathbf{1}, 2}$ information storage, ${ }^{3}$ catalysts, ${ }^{4}$ and environmental treatment. ${ }^{5-8}$ Magnetic nanoparticles are promising for industrial scale wastewater treatment due to their high adsorption capacity, easy separation and enhanced stability. Magnetic nanoparticles can be produced using a variety of synthesis methods and can also be modified with different agents to form nanocomposites for the aforementioned applications.

In metal processing industries, iron and steel parts are often pickled in hydrochloric or sulfuric acid to remove the oxide layer from their surface before undergoing any further processing such as electroplating, metal finishing etc. The pickle solutions are gradually contaminated with dissolved metals

anstitute for Tropical Technology, Vietnam Academy of Science and Technology, Hanoi, Hoang Quoc Viet str. 18, Cau Giay, Hanoi, Vietnam. E-mail: ndung@itt.vast. vn; ltlu@itt.vast.vn

${ }^{b}$ Graduate University of Science and Technology, Vietnam Academy of Science and Technology, Hoang Quoc Viet str. 18, Cau Giay, Hanoi, Vietnam

'Institute for Technology of Radioactive and Rare Elements, Vietnam Atomic Energy Institute, Lang Ha 48, Dong Da, Hanoi, Vietnam

${ }^{d}$ Institute Materials Sciences, Vietnam Academy of Science and Technology, Hanoi, Hoang Quoc Viet str. 18, Cau Giay, Hanoi, Vietnam through usage. As the metal concentration increases, the free acid concentration decreases and the pickling efficiency drops. To retain the high pickling efficiency, fresh concentrated acid is added from time to time to rejuvenate the bath but eventually it becomes spent and must be discarded. The waste generated by metal pickling industries is identified as an environmentally hazardous material.

Due to the high concentration of iron, spent pickling liquors (SPL) are possibly a cheap source of raw material for the production of iron materials. The conventional methods for SPL regeneration and metal recovery have been discussed in a recent detailed review. ${ }^{9}$ Generally, the regeneration of SPL is carried out by oxidizing its dissolved iron chloride $\left(\mathrm{FeCl}_{2}\right)$ in a fluidized bed reactor at about $800{ }^{\circ} \mathrm{C}$ to form ferric oxide $\left(\mathrm{Fe}_{2} \mathrm{O}_{3}\right)$ and gaseous hydrochloric acid. This is a relatively expensive process and it still produces an environmental pollutant, gaseous hydrochloric acid. In addition, the $\mathrm{Fe}_{2} \mathrm{O}_{3}$ recovered product has low economic value. Thus, it is important to develop a process that can produce a more valuable product from SPL with regard to both environmental considerations and processing cost.

For wastewater disinfection, most of the treatment methods involve chemicals and nanomaterials such as chlorine, ozone or Ag nanoparticles. These chemicals and materials possess high antibacterial activity. However, they exhibit some disadvantages: chlorine may harm the environment by forming toxic byproducts such as trihalomethanes and haloacetic acids, which 
are potentially carcinogenic; $;^{10,11}$ ozone has no residual effects but it is sensitive to the presence of organic matters and can produce unknown toxic products; ${ }^{12} \mathrm{Ag}$ nanoparticles may also have negative effects on the environment and human health. ${ }^{13,14}$ Hence, the development of safe antibacterial agents with high recovery or recycling ability has attracted considerable research interest in recent years.

In the last decade, guanidine-based polymers have attracted considerable attention as antibacterial materials due to their excellent biocide efficiency against a wide range of microorganisms. Zhang et al. have tested the antimicrobial activity of some polymeric guanidine and biguanidine salts against 10 bacterial and fungal species, and the determined MIC was not larger than $200 \mu \mathrm{g} \mathrm{mL} \mathrm{mL}^{-1}$. $^{15}$ Polyethylene hexamethylene biguanidine has been demonstrated by Wigdahl et al. to be a promising microbial candidate for anti-HIV compounds. ${ }^{16}$ In addition, polyguanidines have good thermal stability, low corrosive activity and lower toxicity for humans than the currently used disinfectants. ${ }^{17}$ However, the high water solubility restricts their potential application in some cases. There have been some studies reported recently about polyguanidine immobilization on different materials to form nonleaching antibacterial composites. Polyguanidine was used as a grafting agent on polyamide, ${ }^{18}$ polysulfone ${ }^{19}$ or cellulose membranes. ${ }^{20}$ Antibacterial experiments indicated a clearly enhanced antibiofouling performance of the modified filtration membranes. Recently, polyguanidine was also investigated for use in graphene oxide functionalization, in the presence of polyethylene glycol for dispersion improvement. The as-prepared composite material demonstrated an enhanced antibacterial activity against both Gram-negative bacteria Escherichia coli and Grampositive bacteria Staphylococcus aureus. ${ }^{21}$

In our current study, we combine polyguanidine and $\mathrm{Fe}_{3} \mathrm{O}_{4}$ magnetic nanoparticles to construct $\mathrm{Fe}_{3} \mathrm{O}_{4}$ /polyguanidine nanocomposites possessing unique properties such as easy magnetic separation and anti-microbial activity that can be exploited in water purification applications. To the best of our knowledge, this antibacterial $\mathrm{Fe}_{3} \mathrm{O}_{4}$ /polyguanidine magnetic nanocomposite has been synthesized for the first time via the oxidation-precipitation of SPL and modification with polyguanidine. The chemical and phase structures of the product were characterized, and the magnetic properties and antibacterial activity of the sample against E. coli were evaluated.

\section{Materials and method}

\subsection{Chemicals}

Samples of chloride pickling liquors $(\mathrm{pH}$ 0.1-0.2, total iron $151.2 \mathrm{~g} \mathrm{~L} \mathrm{~L}^{-1}$, trace amounts of other heavy metals, e.g. Mn $26.7 \mathrm{mg} \mathrm{L}^{-1}, \mathrm{Cr} 16.9 \mathrm{mg} \mathrm{L}^{-1}$ and $\mathrm{Cu} 9.3 \mathrm{mg} \mathrm{L}^{-1}$ ) were collected from Hoa Phat Steel Factory, Vietnam. Calcium hydroxide $\left(\mathrm{Ca}(\mathrm{OH})_{2}\right)$ of reagent grade was received from Xilong Scientific Co., China. Polyguanidine (Biopag-D) was ordered from FitoLine Co., Russia. All chemicals were used as received without further purification.

\subsection{Preparation of magnetic nanocomposites}

$\mathrm{Fe}_{3} \mathrm{O}_{4}$ nanoparticles were synthesized via an oxidation-precipitation process using spent pickling liquors according to our recent work..$^{22}$ Briefly, $4.5 \mathrm{~mL}$ SPL was added drop-wise into a beaker containing $600 \mathrm{~mL}$ of saturated $\mathrm{Ca}(\mathrm{OH})_{2}$ solution at room temperature. The solution was stirred vigorously in air for about 45 min. The black precipitate of the $\mathrm{Fe}_{3} \mathrm{O}_{4}$ was separated using an external magnet, and was then washed with distilled water until the $\mathrm{pH}$ reached 7 .

For the preparation of the $\mathrm{Fe}_{3} \mathrm{O}_{4}$ /polyguanidine nanocomposite, $2 \mathrm{~g}$ purified $\mathrm{Fe}_{3} \mathrm{O}_{4}$ nanoparticles was added into $20 \mathrm{~mL}$ aqueous polyguanidine solution, $25 \%(\mathrm{w} / \mathrm{w})$. The mixture was sonicated for $5 \mathrm{~min}$ and then stirred mildly for $6 \mathrm{~h}$. The black precipitate was collected using a magnet, and was subsequently rinsed with distilled water and ethanol before being dried at $40{ }^{\circ} \mathrm{C}$ in a vacuum oven.

\subsection{Characterisation}

A field emission scanning electron microscope (FE-SEM, HITACHI S-4800) equipped with an energy dispersive X-ray spectroscope (EDX) was used to examine the morphology and elemental composition of $\mathrm{Fe}_{3} \mathrm{O}_{4}$ and the $\mathrm{Fe}_{3} \mathrm{O}_{4}$ /polyguanidine nanocomposite. X-ray diffraction (XRD) patterns of the synthesized samples were taken with a Siemens/Bruker D5005 X-ray powder diffractometer over a $2 \theta$ range from $10^{\circ}$ to $70^{\circ}$, using $\mathrm{Cu} \mathrm{K}_{\alpha}$ radiation $(\lambda=0.154 \mathrm{~nm})$ with a step size of 0.03 . Fourier transform infrared (FT-IR) spectra were recorded on a Thermo Scientific Nicolet iS10 FT-IR Spectrometer with Diamond ATR. Thermogravimetric analysis (TGA) was performed with a NETZSCH TG $209 \mathrm{~F} 1$ Libra instrument, from $25{ }^{\circ} \mathrm{C}$ to $600{ }^{\circ} \mathrm{C}$ in air (heating rate $10{ }^{\circ} \mathrm{C} \mathrm{min}^{-1}$ ). The magnetic properties of the samples were studied using a vibrating sample magnetometer (VSM, DMS 800, Quantum Design, Inc.). Saturation magnetization $\left(M_{\mathrm{s}}\right)$ and coercive field $\left(H_{\mathrm{c}}\right)$ were measured at room temperature with the magnetic field ranging from -10 to $10 \mathrm{kOe}$.

\subsection{Antibacterial tests}

The disk diffusion method was used to evaluate the antibacterial activity of $\mathrm{Fe}_{3} \mathrm{O}_{4}$ and the $\mathrm{Fe}_{3} \mathrm{O}_{4}$ /polyguanidine nanocomposite against $E$. coli (ATCC 8739). Mueller-Hinton agar was used as the growth medium. Briefly, $8 \mathrm{~mm}$ sterile disks impregnated with the magnetic nanoparticles $(0.5,1.7$ and $5.0 \mathrm{mg} \mathrm{mL}{ }^{-1}$ ) were placed on an E. coli cultured agar plate. After being incubated for $24 \mathrm{~h}$ at $37^{\circ} \mathrm{C}$, the diameter of the inhibition zone was determined.

\section{Results and discussion}

3.1. The influence of synthesis conditions on the magnetic properties

The direct oxidation-precipitation of the SPL in the saturated $\mathrm{Ca}(\mathrm{OH})_{2}$ solution produced magnetic nanoparticles. In the current study, we investigated the influence of synthesis conditions, including the speed of stirring and the volume of the precursor solution, on the morphology and magnetic properties of the nanoparticles. It was found that the magnetic 
Table 1 The dependence of the saturation magnetization value $\left(M_{s}\right)$ on the stirring speed and precursor concentration

\begin{tabular}{llll}
\hline Speed $^{a}(\mathrm{rpm})$ & $M_{\mathrm{s}}\left(\mathrm{emu} \mathrm{g}^{-1}\right)$ & {$\left[\mathrm{Fe}^{2+}\right]^{b}\left(\mathrm{~g} \mathrm{~L}^{-1}\right)$} & $M_{\mathrm{s}}\left(\mathrm{emu} \mathrm{g}^{-1}\right)$ \\
\hline \multirow{2}{*}{00} & 40 & 0.5 & 21 \\
400 & 73.9 & 1.0 & 58 \\
600 & 63 & 1.25 & 74 \\
800 & 22 & 1.5 & 67 \\
& & 2.0 & 58 \\
& & 2.5 & 54
\end{tabular}

${ }^{a}$ The samples were prepared at a precursor concentration of $1.25 \mathrm{~g} \mathrm{~L}^{-1}$. ${ }^{b}$ The samples were stirred at a speed of $400 \mathrm{rpm}$.

properties of the material changed strongly with the variation of stirring speed and precursor concentration. The sample reached the highest $M_{\mathrm{S}}$ value of $74 \mathrm{emu} \mathrm{g}^{-1}$ at the stirring speed and precursor concentration of $400 \mathrm{rpm}$ and $1.25 \mathrm{~g} \mathrm{~L}^{-1}$, respectively (Table 1). This sample was used for our further studies.

For the antibacterial tests, the surface of the sample was modified with polyguanidine to improve its antibacterial activity. Fig. 1 shows the FE-SEM images of the sample before and after modification with the polymer. As shown in Fig. 1a, the iron oxide nanoparticles are fairly monodisperse and have a spherical shape with an average size of about $30 \mathrm{~nm}$. A similar morphology was obtained for the nanocomposite (Fig. 1b).

Fig. 2 shows the XRD patterns of $\mathrm{Fe}_{3} \mathrm{O}_{4}$ and the $\mathrm{Fe}_{3} \mathrm{O}_{4}$ /polyguanidine nanocomposite. The samples show the characteristic diffraction peaks of the structural phase of spinel $\mathrm{Fe}_{3} \mathrm{O}_{4} \cdot{ }^{23}$ This includes the typical peaks of (220), (311), (400), (422), (511) and (440) at the positions 30.2, 35.5, 43.3, 53.7, 57.2 and $62.9^{\circ}$, respectively. The absence of the characteristic diffraction peaks at (113), (210) or (213) of maghemite and hematite ${ }^{24}$ indicates that the nanoparticles synthesized from the spent pickling liquors in our work are single phase. After encapsulating with polyguanidine to form the nanocomposite, no signification change in the phase structure was identified.

The chemical composition of both samples was determined using energy-dispersive X-ray spectroscopy (EDX). The EDX spectra of the nanoparticles synthesized from the spent pickling liquor demonstrate the presence of carbon (5.15\% atomic), as well as $\mathrm{Fe}$ and $\mathrm{O}$, indicating a little impurity of the product
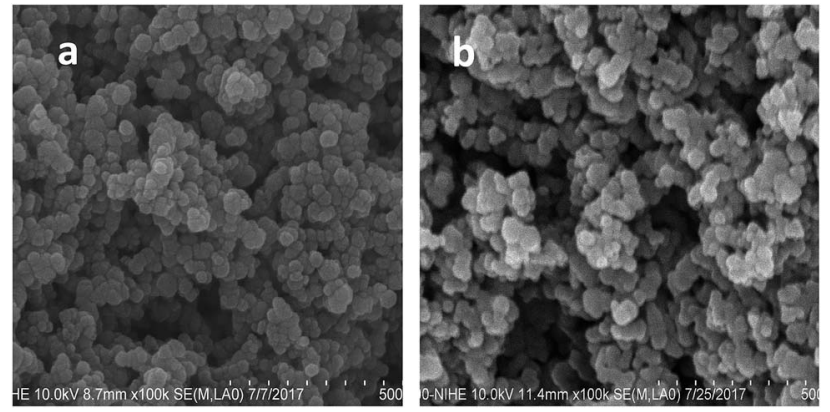

Fig. 1 SEM images of (a) $\mathrm{Fe}_{3} \mathrm{O}_{4}$ and (b) the $\mathrm{Fe}_{3} \mathrm{O}_{4}$ /polyguanidine nanocomposite.

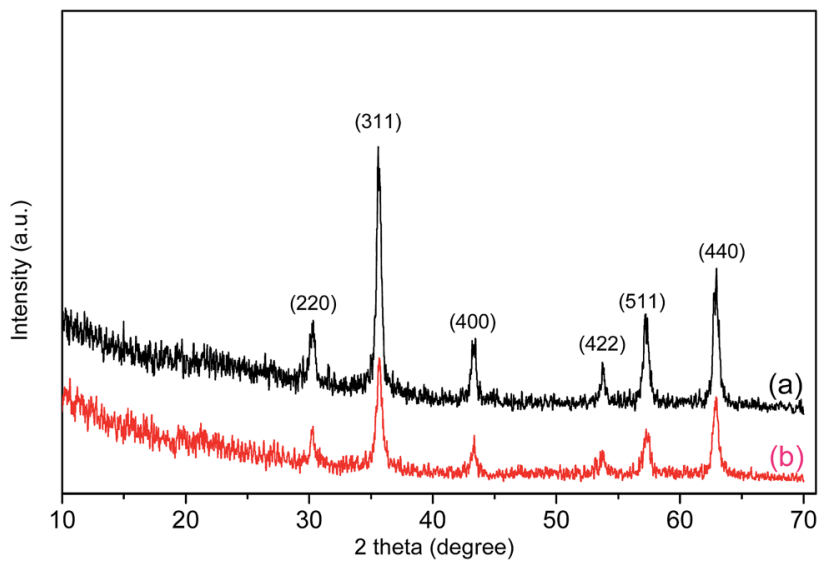

Fig. 2 XRD patterns of $\mathrm{Fe}_{3} \mathrm{O}_{4}$ (a) and the $\mathrm{Fe}_{3} \mathrm{O}_{4}$ /polyguanidine nanocomposite (b) prepared using the SPL precursor.

(Fig. 3a and Table 2). EDX data of the nanocomposite confirm the presence of polyguanidine by showing the coexistence of $\mathrm{Fe}$, $\mathrm{O}, \mathrm{C}, \mathrm{N}$ and $\mathrm{Cl}$ in the spectrum (Fig. 3b and Table 2). From the EDX results, the polyguanidine content in the $\mathrm{Fe}_{3} \mathrm{O}_{4}$ /polyguanidine is determined to be approximately $18 \%(\mathrm{w} / \mathrm{w})$, which is similar to that determined using TGA (see the next section).

\subsection{FT-IR analysis}

FT-IR analysis provides direct evidence for the formation of $\mathrm{Fe}_{3} \mathrm{O}_{4}$ and the $\mathrm{Fe}_{3} \mathrm{O}_{4}$ /polyguanidine nanocomposite (Fig. 4). The FT-IR spectrum of the sole $\mathrm{Fe}_{3} \mathrm{O}_{4}$ nanoparticles (curve a) shows the characteristic absorption band at $576 \mathrm{~cm}^{-1}$, which is attributed to the stretching vibration of the $\mathrm{Fe}-\mathrm{O}$ bond of

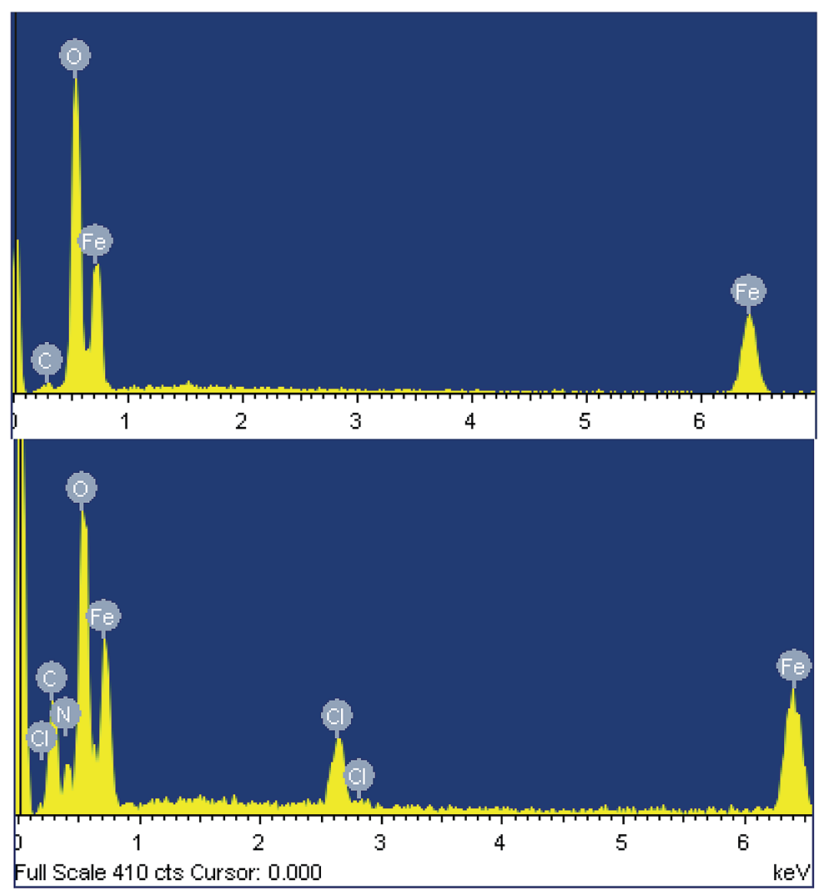

Fig. 3 EDX of $\mathrm{Fe}_{3} \mathrm{O}_{4}$ (above) and $\mathrm{Fe}_{3} \mathrm{O}_{4}$ /polyguanidine nanocomposite (below). 
Table 2 The chemical composition of the $\mathrm{Fe}_{3} \mathrm{O}_{4}$ nanoparticles and $\mathrm{Fe}_{3} \mathrm{O}_{4}$ /polyguanidine nanocomposite determined using EDX ${ }^{a}$

\begin{tabular}{|c|c|c|c|c|}
\hline \multirow[b]{2}{*}{ Element } & \multicolumn{2}{|l|}{$\mathrm{Fe}_{3} \mathrm{O}_{4}$} & \multicolumn{2}{|c|}{$\mathrm{Fe}_{3} \mathrm{O}_{4} /$ polyguanidine } \\
\hline & Weight (\%) & Atomic (\%) & Weight (\%) & Atomic (\%) \\
\hline C K & 2.46 & 5.15 & 15.74 & 29.69 \\
\hline $\mathrm{O} \mathrm{K}$ & 45.29 & 71.29 & 31.67 & 41.73 \\
\hline Fe K & 52.25 & 23.56 & 44.01 & 20.09 \\
\hline $\mathrm{Cl} \mathrm{K}$ & & & 3.34 & 1.85 \\
\hline N K & & & 5.24 & 6.62 \\
\hline Total & 100.00 & & 100.00 & \\
\hline
\end{tabular}

$\mathrm{Fe}_{3} \mathrm{O}_{4} \cdot{ }^{25,26}$ Broad bands at around 3449 and $1634 \mathrm{~cm}^{-1}$ can also be seen, and these should be attributed respectively to the stretching and bending vibrations of the $-\mathrm{OH}$ groups on the surface of the nanoparticles.

In the spectrum of the $\mathrm{Fe}_{3} \mathrm{O}_{4}$ /polyguanidine nanocomposite (curve b), in addition to the absorption peak at $574 \mathrm{~cm}^{-1}$ (which is due to the $\mathrm{Fe}-\mathrm{O}$ stretching vibrations of the $\mathrm{Fe}_{3} \mathrm{O}_{4}$ nanoparticles), one can observe the characteristic absorption peaks of polyguanidine at around 3183.7 and $1466 \mathrm{~cm}^{-1}$, which could be related to the valence and bending vibrations of the amine group, respectively. The $\mathrm{C}-\mathrm{N}$ stretching vibration band at $1355 \mathrm{~cm}^{-1}$ can also be observed, which is due to the existence of the secondary amine from polyguanidine. The peaks at around 2930 and $2865 \mathrm{~cm}^{-1}$ were assigned to the valence asymmetric and symmetric oscillations of the $\mathrm{CH}_{2}$ groups, respectively. The absorption peak at around $1639 \mathrm{~cm}^{-1}$ was very intensive, which was probably due to the overlap of the peak at $1634 \mathrm{~cm}^{-1}$ of $\mathrm{Fe}_{3} \mathrm{O}_{4}$ with the absorption peak of the $\mathrm{C}=\mathrm{N}$ stretching vibration from polyguanidine. The broad peak at around $3449 \mathrm{~cm}^{-1}$ of $\mathrm{Fe}_{3} \mathrm{O}_{4}$ was also displaced to $3408 \mathrm{~cm}^{-1}$ because of the overlap with the peak of the $\mathrm{N}-\mathrm{H}$ vibration from polyguanidine. ${ }^{27}$

\subsection{TGA analysis}

The amount of polyguanidine on the $\mathrm{Fe}_{3} \mathrm{O}_{4}$ surface was determined using thermal analysis TGA. As shown in Fig. 5, the

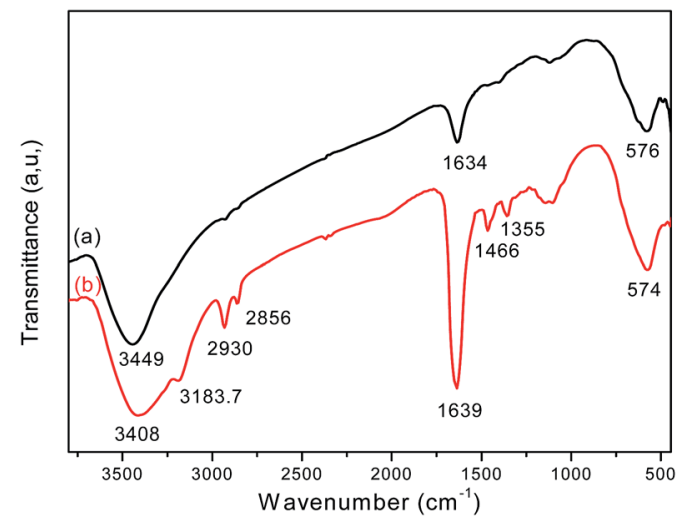

Fig. 4 FT-IR spectra of (a) $\mathrm{Fe}_{3} \mathrm{O}_{4}$ and (b) the $\mathrm{Fe}_{3} \mathrm{O}_{4} /$ polyguanidine nanocomposite.

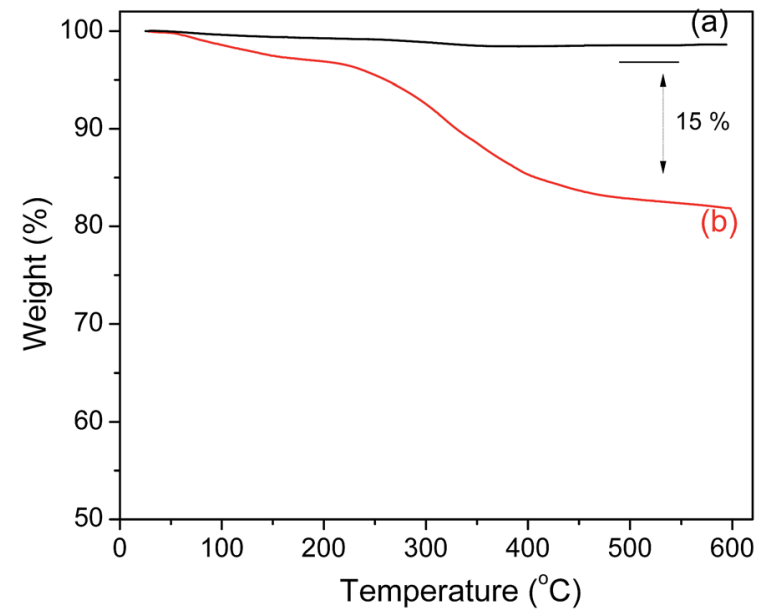

Fig. 5 TGA curves of (a) the $\mathrm{Fe}_{3} \mathrm{O}_{4}$ nanoparticles and (b) the $\mathrm{Fe}_{3} \mathrm{O}_{4} /$ polyguanidine nanocomposite.

$\mathrm{Fe}_{3} \mathrm{O}_{4}$ nanoparticles exhibit very good thermal stability below $600{ }^{\circ} \mathrm{C}$ with insignificant weight loss in the TGA curve. On the other hand, the TGA curve of the nanocomposite indicates a low weight loss of about $5 \%$ starting from room temperature and continuing up to $200{ }^{\circ} \mathrm{C}$ due to dehydration, followed by a more obvious loss of weight starting at 250 and continuing up to $400{ }^{\circ} \mathrm{C}$, which is related to the decomposition of polyguanidine. ${ }^{15}$ The amount of polyguanidine in the nanocomposite is about $15 \%$.

\subsection{Magnetic properties}

The magnetization hysteresis curves of $\mathrm{Fe}_{3} \mathrm{O}_{4}$ and the $\mathrm{Fe}_{3} \mathrm{O}_{4}$ / polyguanidine nanocomposite were obtained using VSM magnetometry under a magnetic field ranging from -10 to 10 kOe at room temperature, and are shown in Fig. 6 . These curves display the high saturation magnetization of both the pure and composite nanoparticles, with no coercivity or remanence, indicating that the samples are super-paramagnetic. As can be

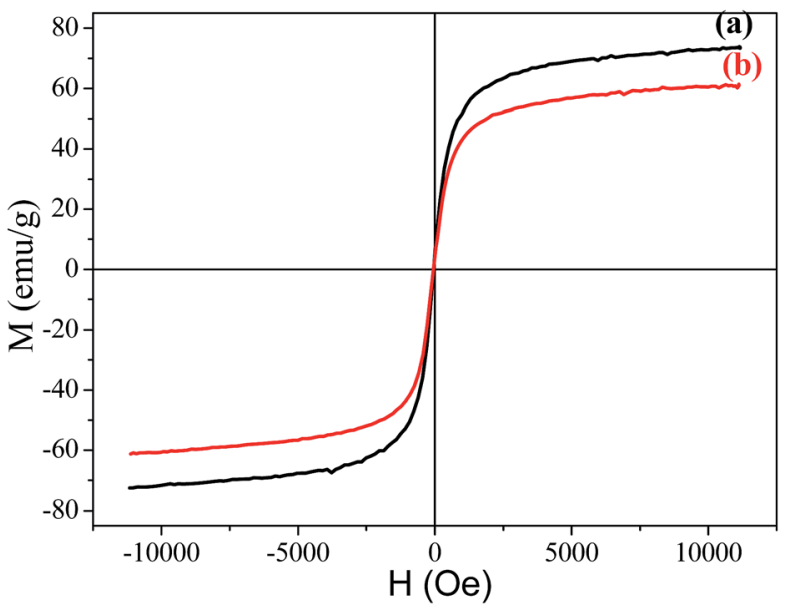

Fig. 6 Magnetization curves of (a) $\mathrm{Fe}_{3} \mathrm{O}_{4}$ and (b) the $\mathrm{Fe}_{3} \mathrm{O}_{4} /$ polyguanidine nanocomposite. 
Table 3 The diameter of the inhibition zone (DIZ) surrounding the sample impregnated disks

\begin{tabular}{lll}
\hline Samples & $\begin{array}{l}\text { Sample concentration } \\
\left(\mathrm{mg} \mathrm{mL}^{-1}\right)\end{array}$ & $\begin{array}{l}\text { DIZ against } \\
\text { E. coli }(\mathrm{mm})\end{array}$ \\
\hline $\mathrm{Fe}_{3} \mathrm{O}_{4}$ & 5.0 & 0 \\
& 1.7 & 0 \\
Pure polyguanidine & 0.5 & 0 \\
& 5.0 & 14 \\
$\mathrm{Fe}_{3} \mathrm{O}_{4}$ /polyguanidine & 1.7 & 8 \\
nanocomposite & 0.5 & 0 \\
& 5.0 & 10 \\
& 1.7 & 4 \\
& 0.5 & 0 \\
\hline
\end{tabular}

observed, the $\mathrm{Fe}_{3} \mathrm{O}_{4}$ nanoparticles synthesized from the SPL exhibit a high magnetic saturation $\left(M_{\mathrm{s}}\right)$ value of $73.9 \mathrm{emu}^{-1}$. However, in the case of the $\mathrm{Fe}_{3} \mathrm{O}_{4}$ /polyguanidine nanocomposite, the $M_{\mathrm{s}}$ value decreases to $61.2 \mathrm{emu} \mathrm{g}^{-1}$ due to the presence of the polymer layer.

\subsection{Antibacterial activity}

In this work, the antibacterial activity of the as-prepared $\mathrm{Fe}_{3} \mathrm{O}_{4}$ and $\mathrm{Fe}_{3} \mathrm{O}_{4}$ /polyguanidine nanocomposite at different concentrations of 5.0, 1.7 and $0.5 \mathrm{mg} \mathrm{mL}^{-1}$ was tested against $E$. coli using the agar diffusion method. Pure polyguanidine (BiopagD) was also tested under similar conditions for comparison. The inhibition zones were determined and are shown in Table 3 and Fig. 7. It can be seen that sole polyguanidine with

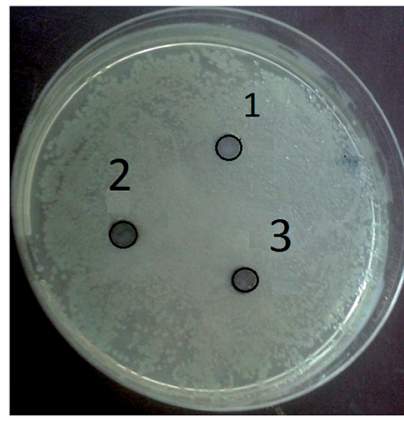

(a)

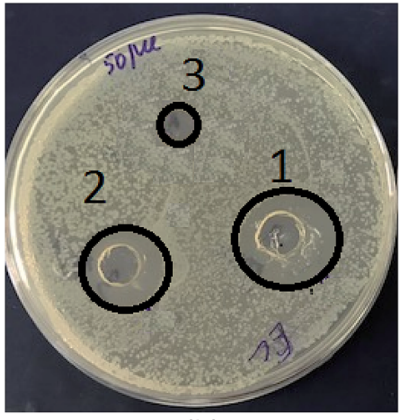

(b)

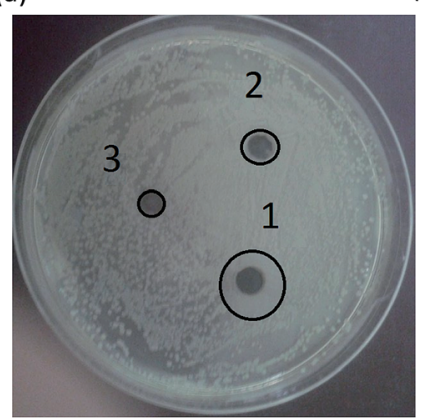

(c)

Fig. 7 Photographs of the antibacterial test results of (a) $\mathrm{Fe}_{3} \mathrm{O}_{4}$, (b) polyguanidine and (c) the $\mathrm{Fe}_{3} \mathrm{O}_{4}$ /polyguanidine nanocomposite at different sample concentrations: (1) 0.5 , (2) 1.7 and (3) $5 \mathrm{mg} \mathrm{mL}^{-1}$. a concentration of $5.0 \mathrm{mg} \mathrm{mL}^{-1}$ presented an inhibition zone of $14 \mathrm{~mm}$ in diameter, which is almost the same as that reported by Grigor'eva et al. ${ }^{27}$ On the other hand, the $\mathrm{Fe}_{3} \mathrm{O}_{4}$ nanoparticles exhibited no antibacterial activity. The synthesized $\mathrm{Fe}_{3} \mathrm{O}_{4} /$ polyguanidine nanocomposite had a relatively high antibacterial effect, presenting an inhibition zone of about $10 \mathrm{~mm}$ when the concentration was $5.0 \mathrm{mg} \mathrm{mL}{ }^{-1}$. With a low content of polyguanidine in the nanocomposite (about 15\%), the obtained results indicate a higher antibacterial efficiency of the $\mathrm{Fe}_{3} \mathrm{O}_{4} /$ polyguanidine nanocomposite material than that of sole polyguanidine.

\section{Conclusion}

In this study, a simple synthesis procedure was developed to prepare a novel magnetic $\mathrm{Fe}_{3} \mathrm{O}_{4} /$ nanocomposite, using spent pickling liquors (SPL) and antibacterial polyguanidine. The analytical results from FE-SEM, EDX and FT-IR measurements indicated that a magnetite $\left(\mathrm{Fe}_{3} \mathrm{O}_{4}\right)$ /polyguanidine nanocomposite with a size of about $30 \mathrm{~nm}$ and a saturation magnetization value of $62.1 \mathrm{emu} \mathrm{g}^{-1}$ was successfully synthesized via oxidation-precipitation in a calcium hydroxide solution of SPL under normal atmospheric pressure and room temperature. The amount of polyguanidine on the surface of the $\mathrm{Fe}_{3} \mathrm{O}_{4}$ nanoparticles was about $15 \%(\mathrm{w} / \mathrm{w})$. This $\mathrm{Fe}_{3} \mathrm{O}_{4} / \mathrm{pol}-$ yguanidine nanocomposite exhibits a high antibacterial activity against Escherichia coli, and we believe that the obtained nanocomposite has the potential to be used in disinfection and biomedical applications. In our next work, the antibacterial activity of the $\mathrm{Fe}_{3} \mathrm{O}_{4}$ /polyguanidine nanocomposite against various types of microorganism (including bacteria, viruses and fungi) will be investigated.

\section{Conflicts of interest}

There are no conflicts to declare.

\section{Acknowledgements}

This research was financially supported by the project from the Vietnam Academy of Science and Technology (code: VAST07.04/ 17-18).

\section{References}

1 A. Wu, P. Ou and L. Zeng, Nano, 2010, 05, 245-270.

2 X. Li, J. Wei, K. E. Aifantis, Y. Fan, Q. Feng, F. Z. Cui, et al., J. Biomed. Mater. Res., Part A, 2016, 104, 1285-1296.

3 E. Cisternas, E. E. Vogel and J. Magn, Magn. Mater., 2015, 388, 35-39.

4 A. Serrà, S. Grauc, C. Gimbert-Surinach, J. Sort, J. Nogués and E. Vallés, Appl. Catal., B, 2017, 217, 81-91.

5 J. R. McCarthy and R. Weissleder, Adv. Drug Delivery Rev., 2008, 60, 1241-1251.

6 H. Maleki, A. Simchi, M. Imami, B. F. O. Costa and J. Magn, Magn. Mater., 2012, 324, 3997-4005. 
7 L. Borlido, A. M. Azevedo, A. C. Roque and M. R. Aires-Barros, Biotechnol. Adv., 2013, 31, 1374-1385.

8 P. Xu, G. M. Zeng, D. L. Huang, C. L. Feng, S. Hu, M. H. Zhao, C. Lai, Z. Wei, C. Huang, G. X. Xie and Z. F. Liu, Sci. Total Environ., 2012, 424, 1-10.

9 A. Devi, A. Singhal and R. Gupta, Int. J. Environ. Sci., 2013, 4(3), 284-295.

10 E. Feliziania, A. Lichterb, J. L. Smilanickc and A. Ippolitod, Postharvest Biol. Technol., 2016, 122, 53-69.

11 N. Hamidin, Q. J. Yu and D. W. Connell, Water Res., 2008, 42(13), 3263-3274.

12 C. P. Chauret, Sanitization, in Encyclopedia of food microbiology, ed. C. A. Batt and M. L. Tortorello, Academic Press, Oxford, 2nd edn, 2014, pp. 360-364.

13 C. Levard, E. M. Hotze, G. V. Lowry and G. E. Brown, Environ. Sci. Technol., 2012, 46, 6900-6914.

14 M. Van der Zande, R. J. Vandebriel, E. Van Doren, E. Kramer, Z. H. Rivera, C. S. Serrano-Rojero, E. R. Gremmer, J. Mast, R. J. Peters, P. C. Hollman, P. J. Hendriksen, H. J. Marvin, A. A. Peijnenburg and H. Bouwmeester, ACS Nano, 2012, 6, 7427-7442.

15 Y. Zhang, J. Jiang and Y. Chen, Polymer, 1999, 40, 6189-6198. 16 F. C. Krebs, S. R. Miller, M. L. Ferguson, M. Labib, R. F. Rando and B. Wigdahl, Biomed. Pharmacother., 2005, 59, 438-445.
17 M. K. Oulé, R. Azinwi, A. M. Bernier, T. Kablan, A. M. Maupertuis, S. Mauler, R. K. Nevry, K. Dembélé, L. Forbes and L. Diop, J. Med. Microbiol., 2008, 57, 15231528.

18 J. Nikkola, X. Liu, Y. Li, M. Raulio, H. L. Alakomi, J. Wei and C. Y. Tang, J. Membr. Sci., 2013, 444, 192-200.

19 X. Li, Y. Cao, H. Yu, G. Kang, X. Jie, Z. Liu and Q. Yuan, J. Membr. Sci., 2014, 466, 82-91.

20 O. Kukharenko, J.-F. Bardeau, I. Zaets, L. Ovcharenko, O. Tarasyuk, S. Porhyn, I. Mischenko, A. Vovk, S. Rogalsky and N. Kozyrovska, Eur. Polym. J., 2014, 60, 247-254.

21 P. Li, S. Sun, A. Dong, Y. Hao, S. Shi, Z. Suna, G. Gao and Y. Chen, Appl. Surf. Sci., 2015, 355, 446-452.

22 L. T. M. Huong, N. V. Tien and N. T. Nhan, Vietnam J. Chem., 2013, 51(6ABC), 654-658.

23 B. Aslibeiki, P. Kameli, I. Manouchehri and H. Salamati, Curr. Appl. Phys., 2012, 12, 812-816.

24 J. Murbe, A. Rechtenbach and J. Topfer, Mater. Chem. Phys., 2008, 110, 426-433.

25 W. Lu, Y. Shen, A. Xie, W. Zhang and J. Magn, Magn. Mater., 2010, 32, 1828-1833.

26 K. Petcharoen and A. Sirivat, Mater. Sci. Eng., B, 2012, 177, 421-427.

27 M. N. Grigor'eva, S. A. Stel'makh, S. A. Astakhova, I. M. Tsenter, L. U. Bazaron, V. B. Batoev and D. M. Mognonov, J. Appl. Polym. Sci., 2014, 131, 40319. 